INDEPENDENT JOURNAL OF MANAGEMENT \& PRODUCTION (IJM\&P)

http://www.ijmp.jor.br

v. 12, n. 4, May-June 2021

ISSN: 2236-269X

DOI: 10.14807/ijmp.v12i4.1375

\title{
DIGITAL TRANSFORMATION IN THE MANUFACTURING INDUSTRY UNDER THE OPTICS OF DIGITAL PLATFORMS AND \\ ECOSYSTEMS
}

\author{
Marcelo T. Okano \\ CEETEPS - UNICAMP, Brazil \\ E-mail: marcelo.okano@cps.sp.gov.br \\ Samira N. Antunes \\ CEETEPS, Brazil \\ E-mail: samira_nascimento@hotmail.com \\ Marcelo Eloy Fernandes \\ CEETEPS, Brazil \\ E-mail: marceloeloyfernandes@gmail.com
}

Submission: 6/18/2020

Revision: 7/30/2020

Accept: 8/20/2020

\section{ABSTRACT}

The new processes for using digital technologies, are requiring manufacturing companies to adapt to these new scenarios, causing a digital transformation. Although the theme Digital transformation is new and current in manufacturing, the way it is being implemented by manufacturing companies is in design and study. Each company adopts or plans its strategy in relation to the digital platform and digital ecosystem. Two digital technologies are widely cited when discussing digital transformation, they are the digital platform and the digital ecosystem. The purpose of this article is to analyze the digital transformation in manufacturing companies from the perspective of digital platforms and ecosystems. In order to answer the research questions, the strategy of this research project was the study of multiple cases with a longitudinal perspective and an exploratory approach. The interview was the main source of data collection. The five platforms studied presented different views of how digital transformation can occur in manufacturing companies, from the simple transaction of matching supplier and consumer to collaborative work with the different stakeholders of the companies.

Keywords: Digital transformation; Digital platform; Digital Ecosystem 
DOI: 10.14807/ijmp.v12i4.1375

\section{INTRODUCTION}

The process of adopting new digital technologies to replace old processes, increment new processes or produce new products, are requiring companies to transform every day and be concerned with items such as customers, business models, new technologies, agile processes and innovations.

These types of processes in manufacturing are increasingly common and are increasingly present in production processes. Manufacturing can be understood as an activity that consists not only in doing things, but in which several people, including end users, can come together and do things in a coded way, doing things through quantified processes, here lies the difference of context between old and new forms of distributed manufacturing (Srai et al., 2016).

Digital technologies are driving these processes, where the main propulsion engines are ICTs (Information and Communication Technologies) and all processes can be considered as being digital.

The role of digital technologies in the transformation of services businesses is poorly investigated according to Ardolino et al. (2018). Some authors consider this type of procedure to be a digital transformation, other authors do not agree with this nomenclature and define it in other ways.

Two digital technologies are widely cited when discussing digital transformation, they are the digital platform and the digital ecosystem. The purpose of this article is to analyze the digital transformation in manufacturing companies from the perspective of digital platforms and ecosystems.

\section{LITERATURE REVIEW}

According to Ardolino et al. (2018), digital technologies facilitate service innovation by manufacturers, enabling new products and service offerings, transforming the structure of supply chains and reshaping competition in the sector.

This innovation can be seen as a digital transformation, several authors try to define this theme.

\subsection{Digital transformation}

Digital Transformation can be defined, according to Ebert and Duarte (2018), as the adoption of disruptive technologies to increase productivity, value creation and social well- 
INDEPENDENT JOURNAL OF MANAGEMENT \& PRODUCTION (IJM\&P)

http://www.ijmp.jor.br

v. 12, n. 4, May-June 2021

ISSN: 2236-269X

DOI: $10.14807 /$ ijmp.v12i4.1375

being. In this sense, Digital Transformation is providing the development of the following types of technologies: collaborative equipment (drones and robots), 3D printing, digital interconnection of objects (IoT - Internet of Things), agile development, blockchain (trust protocol), APIs and Artificial Intelligence (AI). Finally, the authors highlight, in Table 1, that this Digital Transformation has objectives in both the social and economic fields.

Table 1: Objectives of Digital Transformation.

\begin{tabular}{|l|l|}
\hline Perspective & \multicolumn{1}{c|}{ Objectives } \\
\hline \multirow{5}{*}{ Social } & $\begin{array}{l}\text { Promote the development of a more innovative and collaborative culture in industry and } \\
\text { society. }\end{array}$ \\
\cline { 2 - 3 } & $\begin{array}{l}\text { Change the education system to provide new skills and future guidance for people so that they } \\
\text { can achieve excellence in digital work and in society. }\end{array}$ \\
\cline { 2 - 3 } & $\begin{array}{l}\text { Create and maintain digital communication infrastructures and guarantee their governance, } \\
\text { accessibility, quality of service and accessibility. }\end{array}$ \\
\cline { 2 - 3 } & Strengthen digital data protection, transparency, autonomy and trust. \\
\cline { 2 - 3 } & Improve accessibility and quality of digital services offered to the population. \\
\hline \multirow{5}{*}{ Economic } & Implement innovative business models. \\
\cline { 2 - 3 } & Increase income generation, productivity and added value. \\
\cline { 2 - 2 } & Improve the regulatory framework and technical standards. \\
\hline
\end{tabular}

In this scenario, Bharadwaj et al. (2013) highlight that, during the last decade, improvements in information, communication and connectivity technologies have triggered new functionalities. Thus, the following external digital trends provided the basis for the new business infrastructure in the digital age: diffuse connectivity, abundance of information, global supply chains, better IT price / performance, growth of cloud computing and the emergence of Big Data. Therefore, the expanded scope and scale of digital businesses can assist in the execution of the digital business strategy to create differential and create business value, since the speed of decisions and actions is aligned with the speed of market conditions.

For Matt et al. (2015), in recent years, companies have carried out a series of initiatives to explore new technologies and their benefits in the sale of products, processes, and the supply chain. In this scenario, the following essential dimensions, Figure 1, stand out for this strategy related to Digital Transformation: use of technologies, changes in value creation, structural changes and financial aspects. 
DOI: $10.14807 /$ ijmp.v12i4.1375

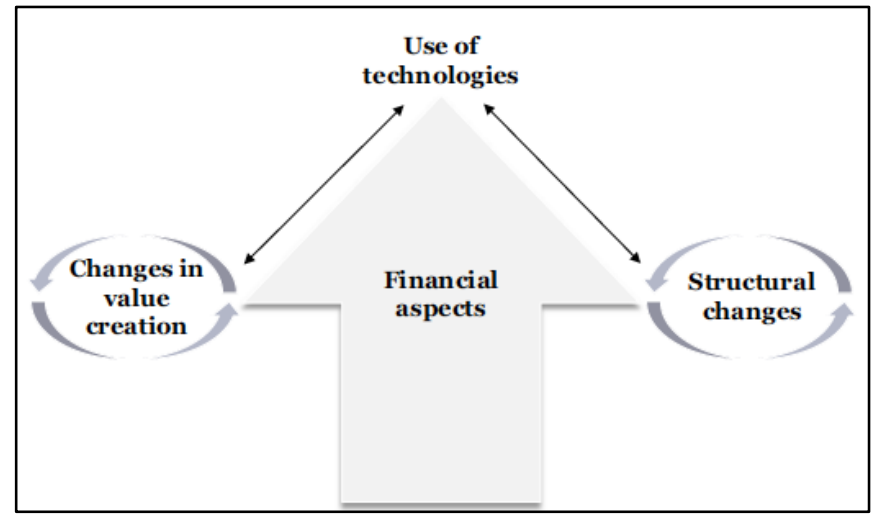

Figure 1: Digital Transformation Framework Source: Matt et al. (2015).

Regarding the use of technology, it stands out as a means to fulfill commercial operations. Thus, it appears that the use of new technologies often implies changes in the creation of value, that is, it may allow adjustments in the scope of companies' businesses.

Therefore, with different technologies in use and different ways of creating value, structural changes (organizational structure) are often necessary to provide an adequate basis for new operations. Finally, the first three dimensions can only be transformed after considering financial aspects, since it is a limiting force in relation to the financing of Digital Transformation.

\subsection{Digital platform}

The concept of digital platform is new in the academic literature and does not have a consensual definition by all authors. Teece and Linden (2017) consider that platforms are not new, digital technologies have broadly expanded their reach, allowing easy interoperability of systems based on common standards and as a result, products that were previously separated are more easily integrated, creating opportunities for new business models. Table 2 shows the definitions and characteristics of the digital platform.

Table 2: Definitions and characteristics of digital platform

\begin{tabular}{|l|l|}
\hline $\begin{array}{l}\text { Digital Platform can be defined as external platforms based on software that } \\
\text { consist of an extensible code base that provides the main functionality shared by } \\
\text { the modules that interact with it and the interfaces through which they } \\
\text { interoperate. The applications (executable part of the software) of the platforms } \\
\text { offer services or systems to end users. }\end{array}$ & $\begin{array}{l}\text { Tiwana et al. (2010) } \\
\text { Ghazawneh and } \\
\text { Henfridsson (2013) }\end{array}$ \\
\hline $\begin{array}{l}\text { A digital platform can also be characterized as a socio- technical set that } \\
\text { encompasses the technical elements (of software and hardware) and the } \\
\text { associated organizational processes and standards. }\end{array}$ & Tilson et al., (2012). \\
\hline $\begin{array}{l}\text { Digital platforms are "actions of a network of companies with complementary } \\
\text { skills to co-innovate new business models that are intrinsically based on } \\
\text { information and technology features". }\end{array}$ & $\begin{array}{l}\text { Venkatraman et al. } \\
\text { (2014) }\end{array}$ \\
\hline
\end{tabular}




\begin{tabular}{|c|c|}
\hline $\begin{array}{l}\text { The multifaceted digital platform is an organization that creates value by } \\
\text { allowing direct communication and interactions between two or more different } \\
\text { groups of users. }\end{array}$ & $\begin{array}{l}\text { Hagiu and Wright } \\
\text { (2015) }\end{array}$ \\
\hline $\begin{array}{l}\text { Digital platforms provide a common set of design rules and a digital } \\
\text { infrastructure to facilitate exchanges between multiple users who would } \\
\text { otherwise never have the opportunity to interact with each other }\end{array}$ & Ondrus et al., (2015) \\
\hline $\begin{array}{l}\text { The platform is built on service-based principles and architecture. That is, it aims } \\
\text { to create a set of services that can be brought together to create applications and } \\
\text { workflows }\end{array}$ & LeHong et al. (2016) \\
\hline $\begin{array}{l}\text { A digital platform is a digital space in which different participants, companies or } \\
\text { consumers, connect, generate and exchange value with each other. Examples } \\
\text { include social media ( Facebook, Instagram), shared economy platforms ( } \\
\text { AirBnb, Uber), e-commerce marketplaces ( Amazon, Mercado Livre), and } \\
\text { streaming services ( Netflix, Spotify, Youtube Music). }\end{array}$ & Castellani , (2016) \\
\hline $\begin{array}{l}\text { A digital platform is a technology-enabled business model that creates value by } \\
\text { facilitating exchanges between two or more interdependent groups. Most } \\
\text { commonly, platforms bring together end users and producers to carry out } \\
\text { transactions with each other. They also allow companies to share information to } \\
\text { improve collaboration or innovation for new products and services. }\end{array}$ & $\begin{array}{l}\text { Morvan , Hintermann, } \\
\text { Vazirani , (2016) }\end{array}$ \\
\hline $\begin{array}{l}\text { A digital platform is a business model with enabled technology allowing } \\
\text { producers and consumers to exchange value. }\end{array}$ & Mancha et al. (2018) \\
\hline $\begin{array}{l}\text { On the Digital Platform, digital economic relationships are built based on a } \\
\text { transparent network environment. That is, the social aspect of trust is provided by } \\
\text { a social network, which is, among other things, a powerful self-development } \\
\text { factor for the entire system and that market infrastructure mechanisms must be } \\
\text { properly implemented }\end{array}$ & $\begin{array}{l}\text { Kozhevnikov and } \\
\text { Korolev (2018) }\end{array}$ \\
\hline $\begin{array}{l}\text { Digital platforms differ in purpose and complexity, from connecting us in our } \\
\text { personal lives to connecting with our customers, colleagues and business } \\
\text { partners. More specifically, the platforms analyze the interaction between the } \\
\text { digital world and the real world and the potential for digital transformation, } \\
\text { trying to fulfill the goal of a multi-stakeholder organization. }\end{array}$ & $\begin{array}{l}\text { ( Bonollo \& Poopuu , } \\
2019\end{array}$ \\
\hline
\end{tabular}

Source: Author

The main characteristics of digital platforms, according to the authors of Table 2 are:

- They are external platforms based on software and hardware;

- Applications offer services or systems to end users;

- It allows the interaction, through the Internet, of different groups of people, companies and organizations;

- Innovates with new business models that are intrinsically based on information and technology features;

- It creates value by allowing direct communication and interactions between groups.

In this article, we adopted the definition by Mancha et al. (2018) for digital platform. For Mancha et al. (2018) a digital platform is a business model with enabled technology allowing producers and consumers to exchange value. In a platform business (Figure 2), producers and consumers create and exchange value through the platform in the form of 
DOI: 10.14807/ijmp.v12i4.1375

information (for example, reviews, behavioral data) and products or services (for example, use of a good transportation service). In addition, the business ecosystem brings complements and technology value to the platform.

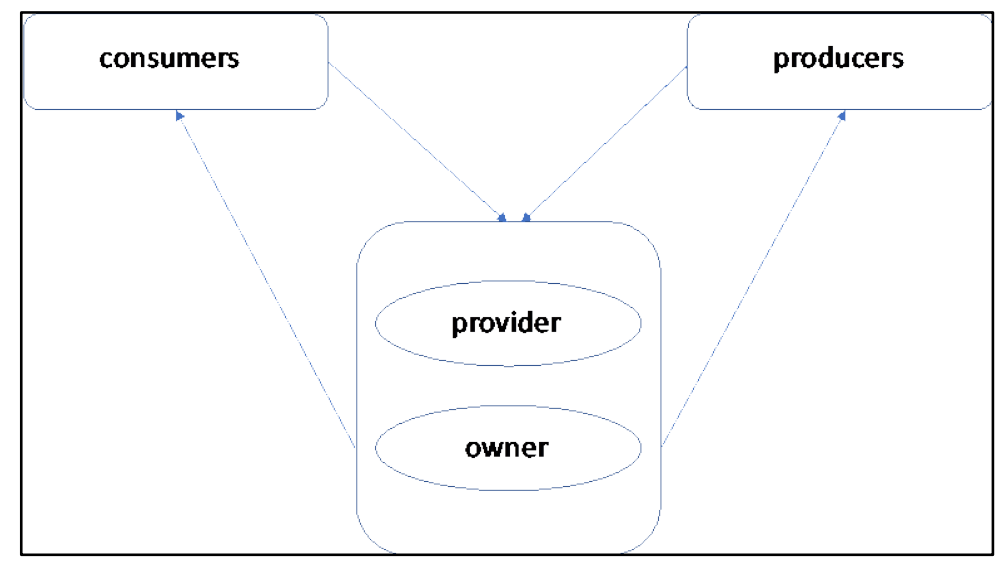

Figure 2: Elements of the platform's business model. Source: Mancha et al. (2018)

Some authors propose ways to classify digital platforms, we will discuss the classifications found in the literature review:

(a) Gawer (2014) and Evans and Gawer (2016) classify platforms according to their main objective and identify approximately three different types of digital platforms:

(1) Transaction platform. sometimes called multi-sided markets or trading platforms. Its main objective is to facilitate transactions between different organizations, entities and individuals, such as connecting buyers with sellers, drivers with passengers, composers with music companies, etc.

(2) Innovation platform. The innovation platforms are formed by technological blocks that provide a basis for the development of services and products. A typical example of an innovation platform is the Android mobile operating system, which allows third-party developers to build applications on top of the operating system. Innovation platforms provide third-party developers with their own set of tools and resources that developers combine and use in order to enable new applications for commercial or other use (Evans \& Gawer, 2016).

(3) Integration platform. Integration platforms combine aspects of the two main types of platform - that is, transaction and innovation platforms (Evans \& Gawer, 2016). It can be argued that any digital transaction platform requires an innovation platform, since, as the name implies, transaction platforms are always built on a specific platform, such as Android, Linux, Windows or whatever. 
DOI: 10.14807/ijmp.v12i4.1375

(b) Smedlund and Faghankhani (2015) classify the types of platforms in terms of investments for front-end ICTs and the amount of collaboration between the participants. Investments in front-end ICTs (for example, Amazon.com's personalized home page for each participant) differentiate platforms from each other (Smedlund, 2012).

There are platforms that consider the front end user experience (UX) to be their top priority and intend to differentiate themselves from their competitors based on user experience. Another distinguishing factor is the amount of collaboration (for example, negotiations, integration, flow of resources and money) between participants in (Smedlund, 2012). The amount of collaboration goes hand in hand with the assumption of a greater number of groups and segments of participants. When this increase, the complexity of the relationship network around the platform increases.

The less restrictions there are on behalf of the platform owner for the participation of participants, the greater the communication and coordination between participants.

Orchestration means facilitating the processes that conduct and promote activities among participants (Dhanaraj \& Parkhe, 2006). By participating in the co-creation of value on the platform, participants form a structure that can be considered as constituting a network, a third governance structure, in addition to markets and hierarchies. Any central actor in the network does not have hierarchical authority over other actors, which means that the network cannot be managed with types of command and control management methods. Figure 3 shows the four categories of platforms.

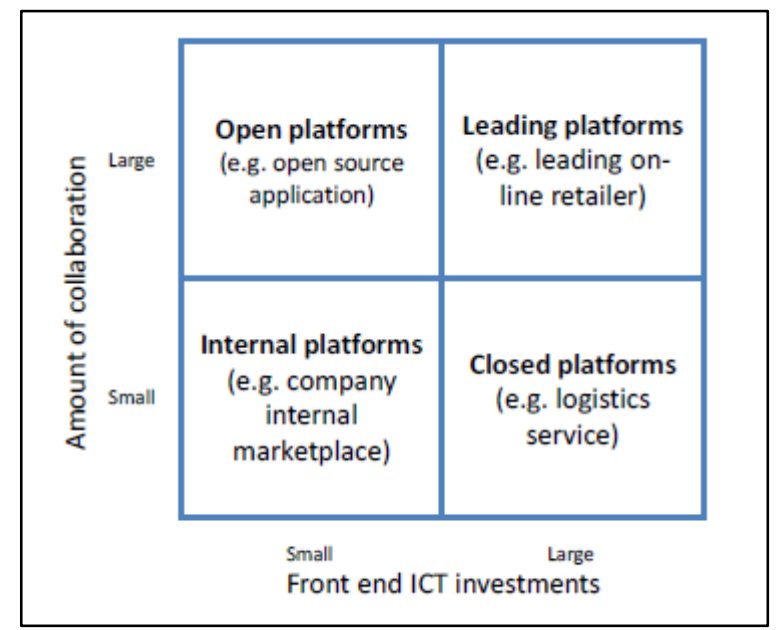

Figure 3: Four categories of platforms

Source: Smedlund and Faghankhani (2015)

(1) Leading platform - attract participants and connect a wide range of end users and complementors, setting high requirements for collaboration and front-end ICTs and 
DOI: 10.14807/ijmp.v12i4.1375

making them highly complex. The orchestration in them should focus on creating new offers with the platform participants. The logic of co-creating value is self-organizing, similar to chaos, and skills are continually being created and renewed. In this case, the orchestrator must facilitate processes that result in ad-hoc interactions, the emergence of new offers and the creation of new knowledge. These activities lead to increased diversity on the platform and improved reach in all business fields.

(2) Internal platform - end users and complementors are well known and specified, making collaboration predictable and ICT systems viable with minimal requirements. Front-end ICTs are not a priority when participants are known because organizational boundaries restrict participation. This type of platform requires orchestration with a focus on efficiency. The goal is to make transactions on the platform as efficient as possible - the more transactions there are, the more efficient it will become. This enables synergies with complementors' offerings by reducing transaction costs for end users. Interdependencies between participants are based on contracts.

(3) Closed platform - the type of end users and complementors are also well known. The platform owner decides whether the participant can join the platform. There are only selected external participants that are related to the platform owner's business (for example, in the case of the parcel delivery tracking system). Participants' attention is directed to specific transactions, requiring requirements for direct and predictable collaboration. Front-end ICTs are important on closed platforms, as the different needs of the end user need to be met with the combination of resources and resources of the participants. In addition, front-end ICTs must be designed in such a way that end users can actively co-create value and possibly serve themselves in a given task, in order to reduce the need for customer service managed by the platform owner.

(4) Open platform - the platform owner does not restrict the participants' options to join it, which are more linked to collaboration and substance, without a platform owner investing heavily in front-end ICTs. End users assemble their own specific combinations of platform offerings, using a front-end ICT system that requires skills and dedication to use.

c) Morvan, Hintermann and Vazirani (2016) classify digital platforms according to the platform business models: 
DOI: 10.14807/ijmp.v12i4.1375

(1) Collaboration - is a type of platform business model that allows internal and / or external partners in the business ecosystem to work together in new ways. For example, FirstBuild allows instructors to share invention ideas with a community and obtain feedback. Collaboration can also take place within the same ecosystem (like the government) or between different ecosystems (like the government and financial services).

(2) Orchestration - is a type of business model that allows business processes for a business ecosystem. Orchestration platforms can also integrate with the platforms of other partners in the business ecosystem, such as supply chain partners and suppliers. For example, PokitDok allows more seamless transactions to take place between healthcare providers, providers and consumers. It orchestrates and connects activities such as scheduling, identity management, connectivity and payments to the business ecosystem.

(3) Creation - is a type of platform business model that allows partners in the business ecosystem to create new applications, products / services, resources and business models. For example, Apple HealthKit provides APIs for developers who can take advantage of the health and activity data from iPhones and Apple Watches. Developers can create mobile apps for iOS and watchOS. YouTube allows providers to create and share content with consumers. Consumers can become suppliers.

(4) Match - is a type of business model that allows providers to find consumers. For example, Uber combines customers with drivers. Airbnb combines owners with people who need a place to stay.

The platform's four types of business models are not mutually exclusive. In fact, most organizations support a hybrid combination of these models, whether on a single opportunity or on multiple opportunities.

\subsection{Digital ecosystems}

Nachira et al. (2007) state that a large part of the value of adopting ICTs derives from its potential to explore and integrate technological networks, knowledge networks and socioeconomic networks, allowing the dynamic creation of new connections, processes and cooperation between economic actors and also that a system those with various types of network cannot be reduced to a technological platform of interoperable services, but must evolve to a process-oriented architecture that can support an environment of knowledge 
INDEPENDENT JOURNAL OF MANAGEMENT \& PRODUCTION (IJM\&P)

http://www.ijmp.jor.br

v. 12, n. 4, May-June 2021

ISSN: 2236-269X

DOI: 10.14807/ijmp.v12i4.1375

representative of users and their socioeconomic and behavioral aspects, or a digital ecosystem.

Table 3 presents the definitions and characteristics of a digital ecosystem.

Table 3: Definitions and characteristics of a digital ecosystem.

\begin{tabular}{|c|c|}
\hline $\begin{array}{l}\text { A Digital Ecosystem is about a new network architecture and a collaborative } \\
\text { environment that addresses the weakness of client-server, point-to-point, network } \\
\text { and web services. }\end{array}$ & Boley and Chang (2007), \\
\hline $\begin{array}{l}\text { Digital ecosystems, similar to natural ones, are self-regulating environments } \\
\text { made up of various "species" such as software, systems, services, business } \\
\text { models, knowledge and regulatory standards that can evolve or become extinct } \\
\text { over time and the evolution of technology. }\end{array}$ & Nachira, (2002) \\
\hline $\begin{array}{l}\text { Android or iOS are not digital innovations from Google and Apple, respectively. } \\
\text { They are digital ecosystems involving hardware, applications and } \\
\text { complementary services orchestrated by Google and Apple and involving several } \\
\text { companies that compete and cooperate in dynamic networks }\end{array}$ & $\begin{array}{l}\text { Iansiti and Levien } \\
\text { (2004). }\end{array}$ \\
\hline $\begin{array}{l}\text { The platform's ecosystem connects two or more sides, creating powerful network } \\
\text { effects, for which the value increases as more members participate. }\end{array}$ & $\begin{array}{l}\text { Morvan, L .; } \\
\text { Hintermann, F .; } \\
\text { Vazirani, (2016) }\end{array}$ \\
\hline $\begin{array}{l}\text { By extending the network paradigm to the social and knowledge layers, the } \\
\text { economic processes and activities that work in cooperation and competition can } \\
\text { be conceptualized as the organisms of an ecosystem, applying the ecosystem } \\
\text { metaphor to its digital representation }\end{array}$ & Nachira et al., 2007 \\
\hline $\begin{array}{l}\text { A digital ecosystem is seen as a combination of a digital platform and the } \\
\text { modules specific to that platform (Figure } 4 \text { ). }\end{array}$ & $\begin{array}{l}\text { Tiwana, Konsynski and } \\
\text { Bush (2010) }\end{array}$ \\
\hline $\begin{array}{l}\text { A digital ecosystem is a self-organizing sustainable system, combining digital } \\
\text { entities and their interrelationships with a focus on interactions between them to } \\
\text { obtain benefits, promote information sharing, increase system usefulness, } \\
\text { cooperation and systems innovation. }\end{array}$ & $\begin{array}{l}\text { Li, Badr and Biennier } \\
\text { (2012) }\end{array}$ \\
\hline $\begin{array}{l}\text { When describing species within a digital environment, Fu (2006) suggests that } \\
\text { species or digital components include components of software, applications, } \\
\text { services, knowledge, business processes and contractual structures. In addition, } \\
\text { Nachira et al. (2007) suggest that software components and agents within a } \\
\text { digital ecosystem can behave independently and self-select and self-adapt. }\end{array}$ & $\begin{array}{l}\text { Fu (2006) } \\
\text { Nachira et al. (2007) }\end{array}$ \\
\hline $\begin{array}{l}\text { The digital ecosystems initiative aims to help local economic actors to become } \\
\text { active participants in globalization, 'valuing' their local culture and vocations and } \\
\text { allowing them to interact and create value networks on a global level }\end{array}$ & Nachira et al. (2007) \\
\hline $\begin{array}{l}\text { Digital ecosystems are designed to evolve under the pressure of economic forces } \\
\text { and to adapt to local conditions. Adaptation and evolution are partly achieved } \\
\text { through the incorporation of evolutionary mechanisms designed in their } \\
\text { architecture and structure, and partly through the participation of local } \\
\text { stakeholders in the process of their development }\end{array}$ & Nachira et al. (2007) \\
\hline
\end{tabular}

Source: Author 
DOI: 10.14807/ijmp.v12i4.1375

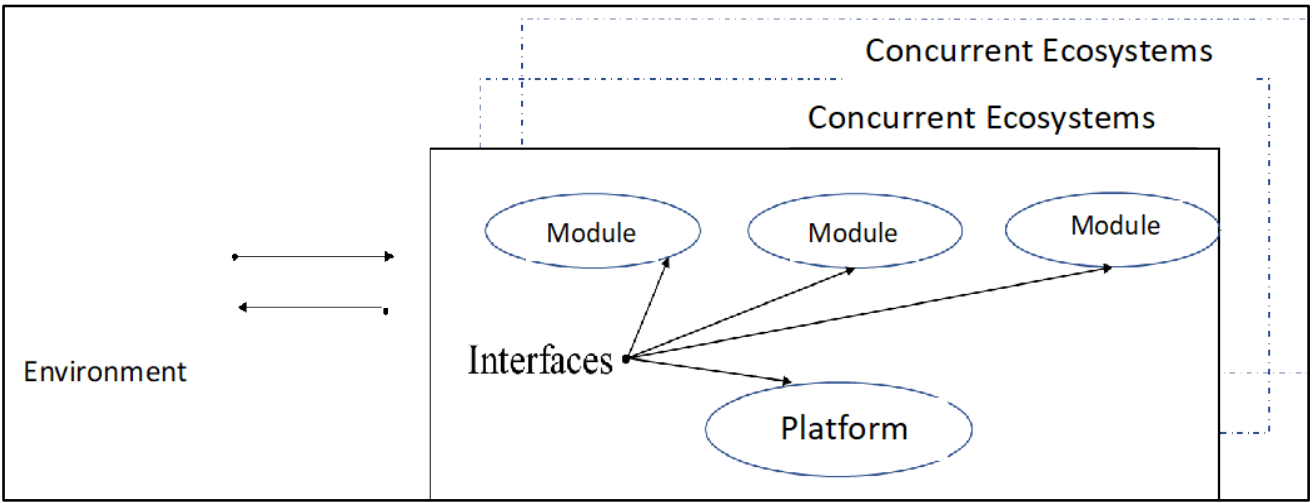

Figure 4: Elements of ecosystems centered on platforms.

Source: Tiwana, Konsynski and Bush (2010)

According to Boley and Chang (2007) the essential aspects of ecosystems are

(1) Interaction and engagement - Species interact with each other for social welfare, to share resources, to find interesting things, and sometimes they need to come together as a group to defend against threats.

(2) Balance - Symbolizes harmony, stability and sustainability within an ecosystem. Species are able to live together and support each other for sustainability.

(3) Aggregated in domains and loosely coupled - Species reach an ecosystem of their own choosing. Each species preserves the environment and is proactive and receptive for its own benefit. They are loosely coupled, even though members have similar culture, social habits, interests and goals.

(4) Self-organization - Each species is independent, self-empowered and self-prepared, committed to self-defense and self-survival.

There are specific differences in communication, agents, functions, etc., if a digital ecosystem is compared to other architectures. For example, in a peer-to-peer architecture, each agent has a predefined role, acting as a client or server, but not both. A grid architecture brings partners together to share resources, but cannot avoid setbacks, while in the architecture of a client server, communication is centralized and acts as a control environment. Finally, the web services network, in which there are intermediaries, service providers and applicants, are 
DOI: $10.14807 /$ ijmp.v12i4.1375

distributed in a hybrid architecture, not guaranteeing service quality or reliability. (Boley \& Chang, 2007).

According to Yoo et al. (2012), successful digital platforms facilitate mechanisms for creating value in the platform ecosystem. These mechanisms for creating value are based on efficient and convenient facilitation of transactions (Tiwana 2014) and the provision of resources, making the digital platform a fertile field for innovation. The mechanisms are:

(1) First mechanism of value creation transactions, digital platforms help suppliers and consumers to find and interact with each other and exchange value in a mutually beneficial way (Evans, 2012).

(2) Second mechanism for creating value refers to the innovation resources of digital platforms that allow partners to create complementary solutions to the core of the platform (Tiwana 2014). The platform owner provides resources, offering development tools to partners, who, in turn, can use these threshold resources to co-create add-ons that add value (Hein et al., 2019).

In this article, the definition of Tiwana, Konsynski and Bush (2010) for digital ecosystem was adopted, as a combination of a digital platform and the specific modules for that platform. A software-based platform is defined as the extensible code base of a softwarebased system, providing functionality shared by modules that operate with it and the interfaces through which they interoperate. A module is a complementary software-based subsystem

\section{RESEARCH METHODOLOGY.}

\subsection{Research questions}

Although the theme Digital transformation is new and current in manufacturing, the way it is being implemented by manufacturing companies is in design and study. Each company adopts or plans its strategy in relation to the digital platform and digital ecosystem.

This study contributes to fill this knowledge gap, exploring the role of the digital platform and digital ecosystem in the digital transformation in manufacturing and the following research questions were elaborated: 
DOI: 10.14807/ijmp.v12i4.1375

(1) What resources can digital platforms assist in the implementation of digital transformation in manufacturing companies?

(2) What resources can digital ecosystems help to implement digital transformation in manufacturing companies?

\subsection{Methodology}

In order to answer the research questions, the strategy of this research project was the study of multiple cases (Yin, 2001) with a longitudinal perspective and an exploratory approach. Conducting this research from this perspective allowed taking into account the different organizational phenomena in a dynamic way from the perspective of movement, change and temporal evolution (Langley, 2007). The interview was the main source of data collection.

For Yin (2001), a case study is: "an empirical investigation that investigates a contemporary phenomenon within its context of real life, and, when the limits between the phenomenon and the context are not clearly defined". And in relation to the research question, the case study seeks to answer "how" and "why" a phenomenon happens; it does not require control over behavioral events; and still has a focus on contemporary events (Yin, 2001)

According to Eisenhardt (1999), case studies can be used to offer a description, test a theory or generate a new theory and are suitable in new areas of topics such as digital transformation, because the developed theory is emerging is situated and developed by recognizing patterns of relationships within and through case studies (Eisenhardt, 1999; Eisenhardt \& Graebner, 2007).

The selection of cases was based on the following criteria: (a) adequate representation of cutting-edge service innovations based on technology, based on a digital platform or digital ecosystem, (b) be a manufacturing company and (c) availability to share information and participate in the study. We selected three large companies in the consumer goods, pharmaceutical and auto parts sectors, totaling 12 respondents among managers, directors and executives.

The information was collected through semi-structured interviews. The consistency of information and adherence to reality were assessed through independent coding and crossed by the researchers. The information collected was complemented and triangulated with secondary sources, such as company documentation, websites and company speeches in public workshops. 
DOI: $10.14807 /$ ijmp.v12i4.1375

\section{CASE STUDY}

\subsection{Company A}

It is a large industry in the consumer goods sector, located in the metropolitan region of São Paulo and, at its request, its name will not be disclosed, it is present in 19 countries, 35 thousand employees in Brazil and almost 100 Distribution Centers direct and 6 Excellence in Brazil.

The company has 3 digital platforms, being:

(1) Microsoft Teams is a unified communication and collaboration platform that combines chat, video conferencing, file storage (including file collaboration) and application integration in the workplace. The service integrates with the Office 365 suite and features extensions that can be integrated with non-Microsoft products.

(2) Salesforce is a platform that provides a customer relationship management (CRM) service and enables the integration of all departments of the company.

(3) The B2B platform is used in electronic commerce to define business transactions between companies, that is, it is an environment where a company (industry, distributor, importer or reseller) markets its products to other companies.

\subsection{Company B}

The company arrived in Brazil in 1930 and the branch was installed in 1944, in Rio de Janeiro. After nine years, the company's operations were transferred to the city of São Paulo, it started to produce its medicines. Since 2002, when the factory underwent a restructuring that lasted 7 years, it opened space to earn in 2003 the ISO 14.001 certificate. The company was elected as one of the 150 Best Companies to Work for in 2017 and 2018 by the magazine Você S / A, in addition to being awarded as one of the Best Companies to Start a Career in 2018. It has approximately 1000 employees in Brazil.

The pharmaceutical company has just launched in Brazil its digital streaming on demand platform, called Empgra01 Play. In order to facilitate the access of health professionals and doctors to content that deepens their knowledge, the virtual space will gather videos about diseases, scientific articles, medicines, coverage of congresses and medical classes.

\subsection{Company $\mathrm{C}$}

The company produces stringers meeting the wide range of specifications present on the market, stamped on the newest HSDP steels (High Strength Dual Phases). The great 
DOI: 10.14807/ijmp.v12i4.1375

expertise in supplying chassis for trucks, buses and pick-ups to the main automakers contributes to the development of projects focused on cost and weight reduction combined with high strength and durability. It has approximately 7000 employees.

The company has a digital platform, SAP is an ERP (Enterprise Resource Planning) that integrates all departments of the company, from HR to the issuance of invoices and highlights SAP HANA with in-memory technology that supports transactional and analytical processes at Big Data levels.

\section{DISCUSSION}

In the light of the theoretical framework presented in Section 2, this section discusses the conclusions of the case studies and addresses the research questions reported in Section 3.1.

\subsection{Digital platform}

The survey of the concept of Digital Platform was mapped through four questions during the interview. Digital Platforms have the following characteristics, according to the literature review:

- They are external platforms based on software and hardware;

- Applications offer services or systems to end users;

- It allows interaction, through the Internet, of different groups of people, companies and organizations;

- Innovates with new business models that are intrinsically based on information and technology features;

- Creates value by allowing direct communication and interactions between groups.

The theoretical models of Gawer (2014) and Evans and Gawer (2016), Smedlund and Faghankhani (2015) and Morvan, Hintermann and Vazirani (2016) were used to classify digital platforms. Table 4 shows the classifications obtained.

Table 4: Classification of the digital platforms surveyed

\begin{tabular}{|l|l|l|l|l|}
\hline Company & Platform / vendor & Main goal & $\begin{array}{l}\text { Investments and amount } \\
\text { of collaboration }\end{array}$ & Business model \\
\hline Company A & Microsoft Teams & Transaction & Internal platform & Collaboration \\
\hline Company A & Salesforce & Transaction & Internal platform & Match \\
\hline Company A & B2B & Transaction & Internal platform & Match \\
\hline Company B & Streaming & Transaction & Closed platform & Collaboration \\
\hline Company C & SAP & Transaction & Internal platform & Match \\
\hline
\end{tabular}


DOI: 10.14807/ijmp.v12i4.1375

The first result related to digital platforms for manufacturing companies was verified in relation to the main objective of the platform. According to the classification of Gawer (2014) and Evans and Gawer (2016), platforms can be classified as transactional, innovation and integration.

The five platforms were classified as transaction platforms, since the main objective is to facilitate transactions between different organizations, entities and individuals. Transaction platforms can be especially useful in reducing transaction costs, allowing different agents to find each other more easily and generally reducing some of the friction in the transaction process (Evans \& Gawer, 2016).

The second verified result is in investments for front-end ICTs and number of forms of collaboration between participants, according to the classification by Smedlund and Faghankhani (2015). According to Smedlund (2012), investments in front-end ICTs are made in developments and schedules to differentiate the platforms, for example, Amazon.com's personalized home page for each participant.

Four platforms have been classified as an internal platform and front-end ICTs are not a priority when participants are known because organizational boundaries restrict participation. In the case of company $\mathrm{B}$, classified as a closed platform, it was found that the companies use the digital platform based on technologies for WEB and the concern is on how to keep the platform available with the growth of new devices and the diversity of interface characteristics, not only in terms of screen size and resolution, but also with supported input and output modes.

Investments in front-end ICTs are important because platform owners want applications to be more specific over time for two reasons: first, greater platform specificity translates into a better end-user experience and greater opportunities to differentiate a platform from rivals. Exploring the unique functionality of a platform means that small improvements in the capabilities of a platform can have a widespread impact on the level of innovation across the ecosystem (Tiwana, 2013).

The third result focuses on the business models of the digital platform, according to Morvan, Hintermann and Vazirani (2016), which classify the platforms according to collaboration, orchestration, creation and correspondence

Among the companies interviewed, it was observed that two of them (Company A and Company B) use the collaboration platform, as Morvan, Hintermann and Vazirani (2016), is a 
DOI: 10.14807/ijmp.v12i4.1375

type of platform business model that allows internal partners and / or external business ecosystems work together in new ways.

Three platforms have already been classified as a correspondence platform (match), which allows producers / suppliers to find consumers. Tiwana (2013) defines it as multilateral, where each "side" refers to a distinct group of stakeholders that the platform brings together. For example, the iOS platform brings together application developers (one side) and end users (other side). These two sides would normally face much higher costs of finding and negotiating with each other without the platform than with it. The platform creates value, making it easier for participants on one side to find those on the other side or mediate their interactions.

\subsection{Digital ecosystem}

The survey of the concept of Digital Ecosystem was mapped through seven questions during the interview. For Boley and Chang (2007), Digital Ecosystems have the following characteristics:

Interaction and engagement: species interact with each other for social welfare, to share resources, to find interesting things and, sometimes, they need to come together as a group to defend against threats;

- $\quad$ Balance: symbolizes harmony, stability and sustainability within an ecosystem. Species are able to live together and support each other for sustainability;

- $\quad$ Aggregated in domains and loosely coupled: the species reach an ecosystem by their own choice. Each species preserves the environment and is proactive and receptive for its own benefit. They are loosely coupled, even though the members have similar culture, social habits, interests and goals;

- $\quad$ Self-organization: each species is independent, self-enabled and self-prepared, committed to self-defense and self-survival.

The theoretical models of digital ecosystems from Tiwana, Konsynski and Bush (2010), Boley and Chang (2007) and Yoo et al., (2012) were used to classify digital platforms. Table 5 shows the classifications obtained.

Table 5: Classification of surveyed digital ecosystems

\begin{tabular}{|l|c|c|c|}
\hline & Company A & Company B & Company C \\
\hline Digital platform & Yes & Yes & Yes \\
\hline Interaction and engagement & Yes & Yes & Yes \\
\hline balance & Yes & Yes & Yes \\
\hline Aggregated in domains and loosely coupled & Yes & Yes & Yes \\
\hline
\end{tabular}


INDEPENDENT JOURNAL OF MANAGEMENT \& PRODUCTION (IJM\&P)

http://www.ijmp.jor.br

v. 12, n. 4, May-June 2021

ISSN: 2236-269X

DOI: 10.14807/ijmp.v12i4.1375

\begin{tabular}{|l|c|c|c|}
\hline Self-organization & Yes & Yes & Yes \\
\hline First transaction engine & Yes & Yes & Yes \\
\hline Second transaction engine & Yes & Yes & Yes \\
\hline
\end{tabular}

Source: Research data

Analyzing the results of Table 5, we find that the three companies presented all the characteristics of a digital ecosystem. In this scenario, it is observed that the majority (81.8\%) of managers have visibility of the Digital Ecosystem in which they operate, while $18.2 \%$, despite the support and scope of activities, have no visibility. In addition, it was possible to observe situations in which the manager was not aware of the term Digital Ecosystem. At other times, some managers understood Digital Ecosystem as Life Cycle because they believed that every service has a growth, maturity and decline, phases related to the obsolescence of technology.

\section{CONCLUSION}

In order to meet the main objective and demystify the digital transformation, through bibliographic analysis, it was possible to identify the main aspects of Digital Transformation that influence manufacturing companies.

Regarding research questions, answering the first research question, digital platforms contribute to creating differential and creating business value, since the speed of decisions and actions is aligned with the speed of market conditions and, consequently, who generates the speed of processes is ICT through platforms.

The five platforms studied presented different views of how digital transformation can occur in manufacturing companies, from the simple transaction of matching supplier and consumer to collaborative work with the different stakeholders of the companies.

Answering the second research question, Digital Transformation is not just a problem from the perspective of the digital platform, since it is necessary to understand what kind of new business models and business opportunities are possible in the Digital Ecosystem.

The three companies surveyed presented the characteristics of digital ecosystems and showed the importance of collaboration with partners, suppliers, customers and other stakeholders along the value chain that involves a more comprehensive exchange of information, including data for strategy planning purposes.

One difficulty encountered is the researcher's bias, which presents itself as a limiting factor to all qualitative research. Although the main objective is to carry out the work 
DOI: 10.14807/ijmp.v12i4.1375

impartially, the researcher is constantly confronting his opinions and assumptions with those presented in the work and this can be a limiting factor.

As future research, we can consider that the topic of digital transformation is quite recent and needs more studies on the subject, opening space for new research that can deepen the topic and approach it from new perspectives.

\section{REFERENCES}

Ardolino, M., Rapaccini, M., Saccani, N., Gaiardelli, P., Crespi, G., \& Ruggeri, C. (2018). The role of digital technologies for the service transformation of industrial companies. International Journal of Production Research, 56(6), 2116-2132.

Bharadwaj, A. et al. (2013 ). Digital business strategy: toward a next generation of insights, MIS Q 37(2), 471-482.

Boley, H., \& Chang, E. (2007). Digital Ecosystems: Principles and Semantics. 2007 Inaugural IEEE-IES Digital EcoSystems and Technologies Conference. 398-403.

Bonollo, N., \& Poopuu, P. (2019). The impact of digital platforms on roles and responsibilities in value creation among stakeholders of an ecosystem.

Briscoe, G., Sadedin, S., \& Paperin, G. (2007). Biology of applied digital ecosystems. In Inaugural IEEE-IES Digital EcoSystems and Technologies Conference (458-463).

Castellani, S. (2016). Everything you need to know about Digital Platforms. Available: http://stephane-castellani.com/everything-you-need-to-know-about-digital-platforms/.

Ebert, C., \& Duarte, C. H. C. (2018). Digital Transformation, IEEE Computer Society,

Eisenhardt, K. M. (1999). Building Theories From Case Study Research. Academy Of Management Review, 14(4), 532-550.

Eisenhardt, K. M., \& Graebner, M. E. (2007). Theory Building From Cases: Opportunities And Challenges. Academy Of Management Journal, 50(1), 25-32.

Evans, D. S. (2012). Governing Bad Behavior By Users Of Multi-Sided Platforms. Berkeley Technology Law Journal, 2(27), 1201-1250.

Evans, P., \& Gawer, A. (2016). The Rise of the Platform Enterprise: A Global Survey (The Emerging Platform Economy Series No. 1). The Center for Global Enterprise

Fu, H. F. H. (2006). Formal Concept Analysis For Digital Ecosystem. 2006 5th International Conference On Machine Learning And Applications (Icmla'06).

Gawer, A. (2014). Bridging differing perspectives on technological platforms: toward an integrative framework. Res. Policy 43(7), 1239-1249

Ghazawneh, A., \& Henfridsson, O. (2013). Balancing Platform Control And External Contribution In Third-Party Development: The Boundary Resources Model. Information Systems Journal 23(2), 173-192.

Hagiu, \& Wright. (2015). Multi-Sided Platforms. International Journal Of Industrial Organization, 43(C), 162-174.

Iansiti, M., \& Levien, R. (2004). Strategy As Ecology. Harvard Business Review, 82(3), 6881. 
DOI: 10.14807/ijmp.v12i4.1375

Itälä, T. (2015). Digital Business And Platforms. In Transition, 50.

Kozhevnikov, D. E., \& Korolev, A. S. (2018). Digital Trust As a Basis For the Digital Transformation Of the Enterprise And Economy. In 2018 Eleventh International Conference" Management of large-scale system development" (MLSD) (1-3). IEEE.

Langley, A. (2007). Process Thinking In Strategic Organization. Strategic Organization, 5(3), 271-282.

Lehong, H. et al. (2016). Building a Digital Business Technology Platform. Gartner, Inc.

Li, W., Badr, Y., \& Biennier, F. (2012). Digital Ecosystems: Challenges And Prospects. In Proceedings Of The International Conference On Management Of Emergent Digital Ecosystems (117-122). ACM.

Lusch, R. F., \& Nambisan, S. (2015). Service Innovation: A Service-Dominant-Logic Perspective. Mis Quarterly, 39, 155-175.

Mancha, R., Gordon, S., \& Iyer, B. F P (2018). A Platform Strategy: A Case Study Of Digital Platform Entrepreneurship. Journal Of Information Technology Case And Application Research, 20(2), 55-70.

Matt, C., Hess, T., \& Benlian, A. (2015). Digital transformation strategies. Business \& Information Systems Engineering, 57(5), 339-343.

Moeuf, A., Pellerin, R., Lamouri, S., Tamayo-Giraldo, S., \& Barbaray, R. (2018). The industrial management of SMEs in the era of Industry 4.0. International Journal of Production Research, 56(3), 1118-1136.

Morvan, L., Hintermann, F., \& Vazirani, M. (2016). Five Ways to Win with Digital Platforms. Accenture Research, Dublin.

Nachira, F., Dini, P., \& Nicolai, A. (2007). A Network Of Digital Business Ecosystems For Europe: Roots, Processes And Perspectives. European Commission, Bruxelles, Introductory Paper, 106.

Nachira, F. (2002). Towards a network of digital business ecosystems fostering the local development.

Ondrus, J., Gannamaneni, A., \& Lyytinen, K. (2015). The Impact Of Openness On The Market Potential Of Multi-Sided Platforms: A Case Study Of Mobile Payment Platforms Journal Of Information Technology, 30(3), 260-275.

Parker, G. G., Van Alstyne, M. W., \& Choudary, S. P. (2016). Platform Revolution: How Networked Markets Are Transforming The Economy - And How To Make Them Work For You. (1st Ed.). New York: W.W. Norton \& Company.

Smedlund, A. (2012). Value Cocreation in Service Platform Business Models, Serv. Sci., vol. 4, no. 1.

Smedlund, A., \& Faghankhani, H. (2016). Platform orchestration for efficiency, development, and innovation. In: 2015 48th Hawaii International Conference on System Sciences. IEEE, 2015. p. 1380-1388.

Srai, J. S., Kumar, M., Graham, G., Phillips, W., Tooze, J., Ford, S., \& Ravi, B. (2016). Distributed manufacturing: scope, challenges and opportunities. International Journal of Production Research, 54(23), 6917-6935.

Teece, D. J., \& Linden, G. (2017). Business models, value capture, and the digital enterprise. J Org Design 6, 8 
DOI: $10.14807 /$ ijmp.v12i4.1375

Tilson, D., Sørensen, C., \& Lyytinen, K. (2012). Change And Control Paradoxes In Mobile Infrastructure Innovation: The Android And Ios Mobile Operating Systems Cases, In: 45th Hawaii International Conference On System Science (Hicss 45), Maui, Hi.

Tiwana, A., Konsynsky, B., \& Bush, A. A. (2010). Platform Evolution: Coevolution Of Platform Architecture, Governance, And Environmental Dynamics. Information Systems Research 21(4), 675-687.

Tiwana, A. (2013). Platform ecosystems: Aligning architecture, governance, and strategy. Newnes.

Vargo, S. L., Maglio, P. P., \& Akaka, M. A. (2008). On Value And Value Co-Creation: A Service Systems And Service Logic Perspective. European Management Journal, 26, 145152.

Venkatraman, N. \& Henderson, J. C. (1998). Real Strategies For Virtual Organizing, Sloan Management Review , 40, 3, 33-48.

Yin, R. K. (2001). Estudo De Caso: Planejamento E Métodos. Porto Alegre: Bookman.

Yin, Y., Stecke, K. E., \& Li, D. (2018). The evolution of production systems from Industry 2.0 through Industry 4.0. International Journal of Production Research, 56(1-2), 848-861.

Yoo, Y., Boland, R. J., Lyytinen, K., \& Majchrzak, A. (2012). Organizing For Innovation In The Digitized World. Organization Science, 23(5), 1398-1408. 